\title{
Sensitivity of Lung Resistance and Compliance to Beta-Blocker Induced Bronchoconstriction and Long Acting Beta-Agonist Withdrawal in COPD
}

\author{
Sunny Jabbal ${ }^{1} \cdot$ Brian J. Lipworth ${ }^{1} \mathbb{C}$
}

Received: 31 October 2017 / Accepted: 4 December 2017 / Published online: 20 December 2017

(c) The Author(s) 2017. This article is an open access publication

\begin{abstract}
Little is known about impulse oscillometry (IOS) in COPD. IOS is an effort independent measure of lung resistance and reactance (compliance). We assessed how frequency dependence of resistance $(\mathrm{R})$ and reactance $(\mathrm{X})$ changed in response to bronchoconstriction with carvedilol followed by long acting beta-agonist (LABA) withdrawal. $N=12$ patients with moderate to severe COPD were analysed, who had $\geq 100 \mathrm{ml}$ fall in $\mathrm{FEV}_{1}$ with carvedilol. Compared to baseline taking ICS/LABA there were 21, 59, and 135\% significant changes in resistance at $5 \mathrm{~Hz}$ (R5), reactance at $5 \mathrm{~Hz}$ (X5), and reactance area (AX), respectively, with carvedilol, while after LABA withdrawal only AX showed a further significant increase to $210 \%$ (i.e. reduced compliance). Hence changes in lung compliance rather than resistance play a more important role in the beta- 2 receptor-mediated responses in COPD.
\end{abstract}

Keywords COPD $\cdot$ Bronchoconstriction · Beta-blocker · IOS · Oscillometry

\section{Introduction}

Little is known about impulse oscillometry (IOS) in COPD. Current diagnosis and management of the disease relies heavily on spirometry, specifically the forced expiratory volume in $1 \mathrm{~s}\left(\mathrm{FEV}_{1}\right)$ and forced vital capacity $(\mathrm{FVC})$ to assess severity of airflow obstruction. Spirometry unlike IOS is effort dependent and is therefore susceptible to artificial effects of forced expiratory airway closure. IOS is more physiologic being performed with normal tidal breathing, using sound waves of varying frequencies to detect changes in respiratory resistance $(\mathrm{R})$ and reactance $(\mathrm{X})$. In this regard, reactance and compliance are related in reciprocal manner. Changes in airway compliance are thought to reflect the degree of hyperinflation in COPD [1].

Sunny Jabbal and Brian J. Lipworth have contributed equally to the work and have read and approved the submission.

Brian J. Lipworth

b.j.lipworth@dundee.ac.uk

1 Scottish Centre for Respiratory Research, Ninewells Hospital and Medical School, Dundee, Scotland DD1 9SY, UK
A post hoc analysis of ECLIPSE in 2054 patients with COPD demonstrated that airway resistance at $5 \mathrm{~Hz}$ but not $20 \mathrm{~Hz}$ increased modestly comparing GOLD groups 2 and 4, but airway compliance (as integrated area of low frequency reactance, AX) increased by a much larger degree [2]. Furthermore healthy controls and smokers had mean AX values of 0.38 and $0.34 \mathrm{kPa} / \mathrm{L} / \mathrm{s} \mathrm{Hz}$, whereas even GOLD group 2 patients had a mean $\mathrm{AX}$ of $1.37 \mathrm{kPa} / \mathrm{L} / \mathrm{s} \mathrm{Hz}$, in turn suggesting that reduced lung compliance plays an important role in the early pathophysiology of the disease.

Airway compliance as AX or reactance at $5 \mathrm{~Hz}$ (X5) has been shown to be closely associated with changes in $\mathrm{FEV}_{1}$ $[2,3]$, more so than resistance as R5. There are few data on changes in IOS in response to bronchoconstrictor stimuli in patients with COPD. In one study, there was discordance between R5 and X5 in response to methacholine bronchoconstriction in COPD, while in asthma there was concordance in response [4]. 


\section{Methods}

Here, we report on a post hoc responder analysis of the carvedilol arm of NCT01656005 [5]. This study had favourable opinion from the East of Scotland Research and Ethics Committee (12/ES/0054). In brief, patients with moderate to severe COPD received an initial runin of 2 weeks with ICS/LABA as beclometasone $100 \mu \mathrm{g} /$ formoterol $6 \mu \mathrm{g} 2$ puffs bid (Fostair, Chiesi, Manchester, UK). At baseline after run-in, while still receiving ICS/ LABA, patients received weekly dose titration with the non-selective beta-blocker carvedilol to achieve a target dose of $12.5 \mathrm{mg}$ bid, which was then given in conjunction with a further 1 week on ICS/LABA. This was followed by LABA withdrawal with a further week to ICS alone as beclometasone $200 \mu \mathrm{g} 2$ puffs bid (Clenil, Chiesi) in the presence of continued carvedilol. Patients had lung function tests at baseline (SuperSpiro, Micro Medical Ltd, Chatham, Kent, United Kingdom) and IOS (Jaeger Masterscreen IOS, Hochberg, Germany) on no beta-blocker while taking ICS//LABA and subsequently while taking carvedilol in conjunction with ICS/LABA and ICS alone.

We carried out a responder analysis, selecting those patients $(n=12)$ who exhibited a decrease in $\mathrm{FEV}_{1}$ of $\geq 100 \mathrm{ml}$, i.e. above the MCID [6] in response to carvedilol while taking concomitant ICS/LABA. We calculated percentage change in $\mathrm{AX}, \mathrm{X} 5, \mathrm{R} 5, \mathrm{R} 20, \mathrm{FEV}_{1}$ and $\mathrm{FVC}$ comparing pre beta-blocker baseline (on ICS/LABA) to carvedilol plus either ICS/LABA or ICS alone. We also calculated standardised response means (SRM), which are a relative measure of effect size and responsiveness and so express the signal (mean)-to-noise (standard deviation) ratio [7]. An SRM of 0.8 units or greater is considered highly sensitive, and because they are standardised scores, they can be compared between variables [7].

\section{Results}

Patients had a mean age 65 years, mean smoking pack year history of 53, mean $\mathrm{FEV}_{1} 52 \%$ predicted, and mean $7 \%$ reversibility of $\mathrm{FEV}_{1}$ to salbutamol $400 \mu \mathrm{g}$. Percentage change from baseline in IOS (R5, R20, X5, AX) and $\mathrm{FEV}_{1}$ are depicted in Fig. 1. In terms of airway resistance, R5 increased significantly from the presence of carvedilol, while no further increase in R5 occurred when the LABA was withdrawn. In contrast, there was no significant change in R20 at any point.

In terms of reactance, there was a significant increase (i.e. reduced compliance) in both $\mathrm{X} 5$ and $\mathrm{AX}$ in the presence of carvedilol, however only $\mathrm{AX}$ increased

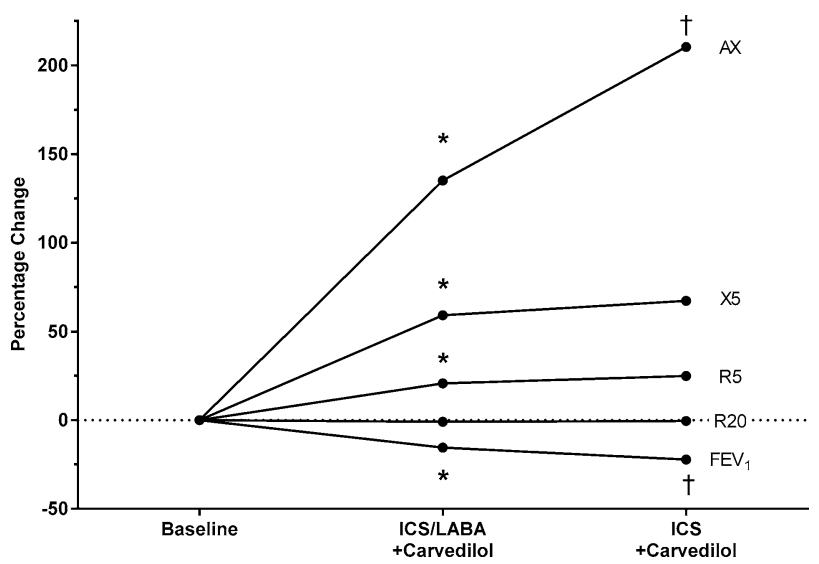

Fig. 1 Comparison of percentage change from baseline (on ICS/ LABA without beta-blocker) in reactance (i.e. compliance: $\mathrm{AX}, \mathrm{X} 5$ ) and resistance (R5, R20), and forced expiratory volume in $1 \mathrm{~s}\left(\mathrm{FEV}_{1}\right)$. Asterisk denotes $P<0.05$ versus baseline, cross denotes $P<0.05$ versus ICS/LABA

significantly more after LABA withdrawal. FEV 1 decreased significantly in the presence of carvedilol and decreased significantly further after LABA withdrawal, while FVC was only reduced after LABA withdrawal. SRM's (Table 1) for reactance were higher than those for resistance, with AX being greater than X5.

\section{Discussion}

In patients receiving ICS/LABA, carvedilol challenge produced no significant change in R20, in turn suggesting that larger airways are not involved in $\beta 2$-mediated bronchoconstriction in COPD. Previous data have also shown that R20 is unrelated to airflow obstruction or lung hyperinflation in COPD [3, 8]. It is known that LABA reduces lung hyperinflation [9] as measured by RV, and that in turn reactance is related to $\mathrm{RV}$ - in other words hyperinflation and compliance appear to go hand in hand [10]. This is supported by using FVC as a surrogate for air trapping in COPD, where our data showed a $17 \%$ decrease in FVC comparing ICS alone to ICS/LABA in the presence of carvedilol. It is worth pointing out that the presence of emphysema would be expected to increase compliance due to loss of elastic lung recoil [11]. However, emphysema also results in reduced airway support due to loss of alveolar attachments, manifesting as small airway closure. Hence the net result of reduced compliance presumably reflects the relative dominance of small airways closure in response to beta- 2 antagonism and LABA withdrawal. The finding of increased small airway resistance was evident as heterogeneity of resistance between 5 and $20 \mathrm{~Hz}$ (R5-20) is also in keeping with alerted small airways geometry. 
Table 1 Mean (95\% CI) differences as change from baseline (on ICS/LABA without beta-blocker): in forced expiratory volume in $1 \mathrm{~s}$ (FEV1), and impulse oscillometry values of resistance (R) at $5 \mathrm{~Hz}$
(R5) and $20 \mathrm{~Hz}(\mathrm{R} 20)$ and reactance (X) at $5 \mathrm{~Hz}$ (X5) and area under the curve (AX), with standardised response means (SRM)

\begin{tabular}{|c|c|c|c|}
\hline & \multicolumn{3}{|l|}{ Carvedilol + ICS/LABA } \\
\hline & Mean difference $(95 \% \mathrm{CI})$ & $P$ & SRM \\
\hline FEV1 (L) & $-0.21(-0.27,-0.15)$ & $<0.001$ & 2.21 \\
\hline $\mathrm{FVC}(\mathrm{L})$ & $-0.22(-0.44,-0.01)$ & 0.046 & 0.65 \\
\hline $\mathrm{R} 5(\mathrm{kPa} / \mathrm{L} / \mathrm{s})$ & $0.10(0.01,0.19)$ & 0.03 & 0.72 \\
\hline $\mathrm{R} 20(\mathrm{kPa} / \mathrm{L} / \mathrm{s})$ & $-0.01(-0.05,0.03)$ & 0.55 & 0.18 \\
\hline $\mathrm{X} 5(\mathrm{kPa} / \mathrm{L} / \mathrm{s})$ & $-0.10(-0.16,-0.05)$ & $<0.001$ & 1.19 \\
\hline \multirow[t]{3}{*}{$\mathrm{AX}(\mathrm{kPa} / \mathrm{L} / \mathrm{s} \mathrm{Hz})$} & $1.46(0.63,2.29)$ & $<0.001$ & 1.11 \\
\hline & \multicolumn{3}{|l|}{ Carvedilol + ICS } \\
\hline & Mean difference $(95 \% \mathrm{CI})$ & $P$ & SRM \\
\hline FEV1 (L) & $-0.30(-0.39,-0.20)$ & $<0.001$ & 2.08 \\
\hline $\mathrm{FVC}(\mathrm{L})$ & $-0.60(-0.85,-0.35)$ & $<0.001$ & 1.52 \\
\hline $\mathrm{R} 5$ (kPa/L/s) & $0.11(0.01,0.21)$ & 0.03 & 0.72 \\
\hline $\mathrm{R} 20(\mathrm{kPa} / \mathrm{L} / \mathrm{s})$ & $-0.02(-0.07,0.03)$ & 0.50 & 0.20 \\
\hline $\mathrm{X} 5(\mathrm{kPa} / \mathrm{L} / \mathrm{s})$ & $-0.10(-0.17,-0.03)$ & 0.01 & 0.90 \\
\hline $\mathrm{AX}(\mathrm{kPa} / \mathrm{L} / \mathrm{s} \mathrm{Hz})$ & $1.70(1.08,2.32)$ & $<0.001$ & 1.74 \\
\hline
\end{tabular}

The higher the SRM the better the signal to noise ratio for a given variable. Mean baselines values were as follows: FEV1 1.43 L, FVC 3.55 L, R5 $0.60 \mathrm{kPa} / \mathrm{L} / \mathrm{s}, \mathrm{R} 200.39 \mathrm{kPa} / \mathrm{L} / \mathrm{s}, \mathrm{X} 5-0.27 \mathrm{kPa} / \mathrm{L} / \mathrm{s}, \mathrm{AX} 2.69 \mathrm{kPa} / \mathrm{L} / \mathrm{s} \mathrm{Hz}$

In terms of bronchodilator response in COPD, tiotropium and tulobuterol have been shown to produce significantly additive effects on X5, AX, R5 but not R20 [8]. Accordingly in terms of bronchoconstriction in our patients, there was a significant increase in R5, but not R20, and an increase in AX, and X5. This was in keeping with the ECLIPSE cohort, where AX rather than R5 more closely followed COPD severity defined by FEV1, while R20 was unchanged [2]. Our data were also similar to in TORCH [12], where ICS/ LABA was significantly different to ICS alone on $\mathrm{FEV}_{1}$. This is perhaps unsurprising since our patients were selected a priori on the basis of a fall in FEV1 while taking ICS/ LABA with carvedilol. In terms lung compliance, both AX and X5 increased significantly after carvedilol; however, only AX significantly increased after removal of LABA. AX represents lung compliance component of low-frequencydependent reactance, and appears to be more sensitive than reactance measured at $5 \mathrm{~Hz}$ (X5), for identifying increasing changes in response to combined $\beta_{2}$-receptor antagonism and agonism.

The limitations of our analysis are its small sample size, and lack of corroboration of reactance (AX, X5) with static lung volumes such as RV/TLC ratio. Moreover, we did not measure the within breath differences between inspiratory and expiratory reactance as a measure of dynamic hyperinflation, for the pragmatic reason that this is not performed in our routine clinical practice. We also acknowledge that we did not perform CT imaging to define the degree of emphysema nor did we evaluate ventilation heterogeneity using multiple breath nitrogen washout. Nonetheless, using FVC as a crude surrogate for air trapping, we did observe a significant reduction in response to carvedilol in conjunction with LABA withdrawal.

This analysis provides evidence that reduced lung compliance (as AX) measured by IOS is a sensitive outcome in response to bronchoconstriction in COPD. It would be relevant to know if exacerbation frequency and symptoms are more closely related to alterations in compliance than resistance, and in turn whether lung compliance might be a potential target for long acting bronchodilator therapy, for example comparing ICS/LABA/LAMA to ICS/LABA.

Funding The study was partially funded by TENOVUS Scotland (Grant No. T12/28) as well as from existing departmental unrestricted grant funds.

\section{Compliance with Ethical Standards}

Conflict of interest Dr. Jabbal reports personal fees and non-financial support from Chiesi Pharma, personal fees and non-financial support from Pfizer, non-financial support and other from Napp, personal fees and non-financial support from AstraZeneca, personal fees from Boehringer Ingelheim, non-financial support from TEVA, outside the submitted work. Dr. Lipworth reports grants, personal fees and nonfinancial support from Chiesi, grants, personal fees, non-financial support and other from Boehringer Ingelheim, grants and personal fees from Meda, grants, personal fees and non-financial support from Teva, grants from Janssen, grants from AstraZeneca, grants from Roche, per- 
sonal fees from Dr Reddys, personal fees from Cipla, personal fees from Lupin, personal fees from Sandoz, grants from Sanofi, outside the submitted work.

Ethical Approval All procedures performed in studies involving human participants were in accordance with the ethical standards of the institutional and/or national research committee and with the 1964 Helsinki declaration and its later amendments or comparable ethical standards.

Informed Consent Informed consent was obtained from all individual participants included in the study.

Open Access This article is distributed under the terms of the Creative Commons Attribution 4.0 International License (http://creativecommons.org/licenses/by/4.0/), which permits unrestricted use, distribution, and reproduction in any medium, provided you give appropriate credit to the original author(s) and the source, provide a link to the Creative Commons license, and indicate if changes were made.

\section{References}

1. Brashier B, Salvi S (2015) Measuring lung function using sound waves: role of the forced oscillation technique and impulse oscillometry system. Breathe (Sheff) 11:57-65

2. Crim C, Celli B, Edwards LD, Wouters E, Coxson HO, Tal-Singer $R$ et al (2011) Respiratory system impedance with impulse oscillometry in healthy and COPD subjects: ECLIPSE baseline results. Respir Med 105(7):1069-1078

3. Kolsum U, Borrill Z, Roy K, Starkey C, Vestbo J, Houghton C et al (2009) Impulse oscillometry in COPD: identification of measurements related to airway obstruction, airway conductance and lung volumes. Respir Med 103(1):136-143

4. Walker PP, Hadcroft J, Costello RW, Calverley PM (2009) Lung function changes following methacholine inhalation in COPD. Respir Med 103(4):535-541
5. Jabbal S, Anderson W, Short P, Morrison A, Manoharan A, Lipworth BJ (2017) Cardiopulmonary interactions with beta-blockers and inhaled therapy in COPD. J Assoc Phys QJM. https://doi. org/10.1093/qjmed/hcx155

6. Jones PW, Beeh KM, Chapman KR, Decramer M, Mahler DA, Wedzicha JA (2014) Minimal clinically important differences in pharmacological trials. Am J Respir Crit Care Med 189(3):250-255

7. Short PM, Williamson PA, Lipworth BJ (2012) Sensitivity of impulse oscillometry and spirometry in beta-blocker induced bronchoconstriction and beta-agonist bronchodilatation in asthma. Ann Allergy Asthma Immunol 109(6):412-415

8. Abe T, Setoguchi Y, Kono Y, Togashi Y, Sugiyama S, Tanakadate $\mathrm{M}$ et al (2011) Effects of inhaled tiotropium plus transdermal tulobuterol versus tiotropium alone on impulse oscillation system (IOS)-assessed measures of peripheral airway resistance and reactance, lung function and quality of life in patients with COPD: a randomized crossover study. Pulm Pharmacol Ther 24(5):617-624

9. Watz H, Troosters T, Beeh KM, Garcia-Aymerich J, Paggiaro P, Molins E et al (2017) ACTIVATE: the effect of aclidinium/ formoterol on hyperinflation, exercise capacity, and physical activity in patients with COPD. Int J Chron Obstruct Pulmon Dis $12: 2545-2558$

10. Haruna A, Oga T, Muro S, Ohara T, Sato S, Marumo S et al (2010) Relationship between peripheral airway function and patient-reported outcomes in COPD: a cross-sectional study. BMC Pulm Med 10:10

11. Papandrinopoulou D, Tzouda V, Tsoukalas G (2012) Lung compliance and chronic obstructive pulmonary disease. Pulm Med 2012:542769

12. Calverley PM, Anderson JA, Celli B, Ferguson GT, Jenkins C, Jones PW et al (2007) Salmeterol and fluticasone propionate and survival in chronic obstructive pulmonary disease. N Engl J Med 356(8):775-789 